\title{
广西北流型古代铜鼓的铅同位素考证
}

\author{
彭子成 \\ （中国科技大学地球和空间科学系，合肥） \\ 万辅棌 姚舜安 \\ （广西民族学院，南宁）
}

近 10 年来应用铅同位素来研究古代器物,如青铜器、钱币、玻璃、颜料和陶釉等,在国外已 有了积极的开展。人们利用古物中铅同位素比值的分布特征、相互联系，以及与矿料产地的 关系，并结合文史资料，为研究古代社会的制造业、贸易、交通和文化交流等问题开拓了一条新 的途径. 值得注意的是,目前有一批美国、日本、澳大利亚的学者,已用了此种方法来研究我国 的古玻璃和青铜器,并取得了十分有意义的成果 ${ }^{[1]}$, 这应引起我国的科技史界、考古学界和史 学界的重视.

早在六十年代在矿床地质学领域中就已开始应用铅同位素 $\left({ }^{200} \mathrm{~Pb},{ }^{200} \mathrm{~Pb},{ }^{200} \mathrm{~Pb},{ }^{200} \mathrm{~Pb}\right)$ ．这 些铅同位妻可作为“指纹”来探索成矿条件、成矿过程、矿质来源和矿床成因等问题. 在一定的 地质条件下当矿石铅形成以后,即脱离了原矿液(或岩浆)中的铀针体系,使其铅同位素比值能 保持至今不变的特点,这就构成了用铅同位素比值法来追溯矿料来源的依据 ${ }^{[1]}$.

铜鼓是我国南方少数民族地区具有代表性的一种历史文物。本文研究的广西北流型铜 鼓,广泛分布于北流县及其邻区，如容县、岑溪、陆川等地. 在 1966 年经考古发现处于北流县 内的铜石岭是一处从汉代延至隋代的冶铜遗址 ${ }^{[2]}$.

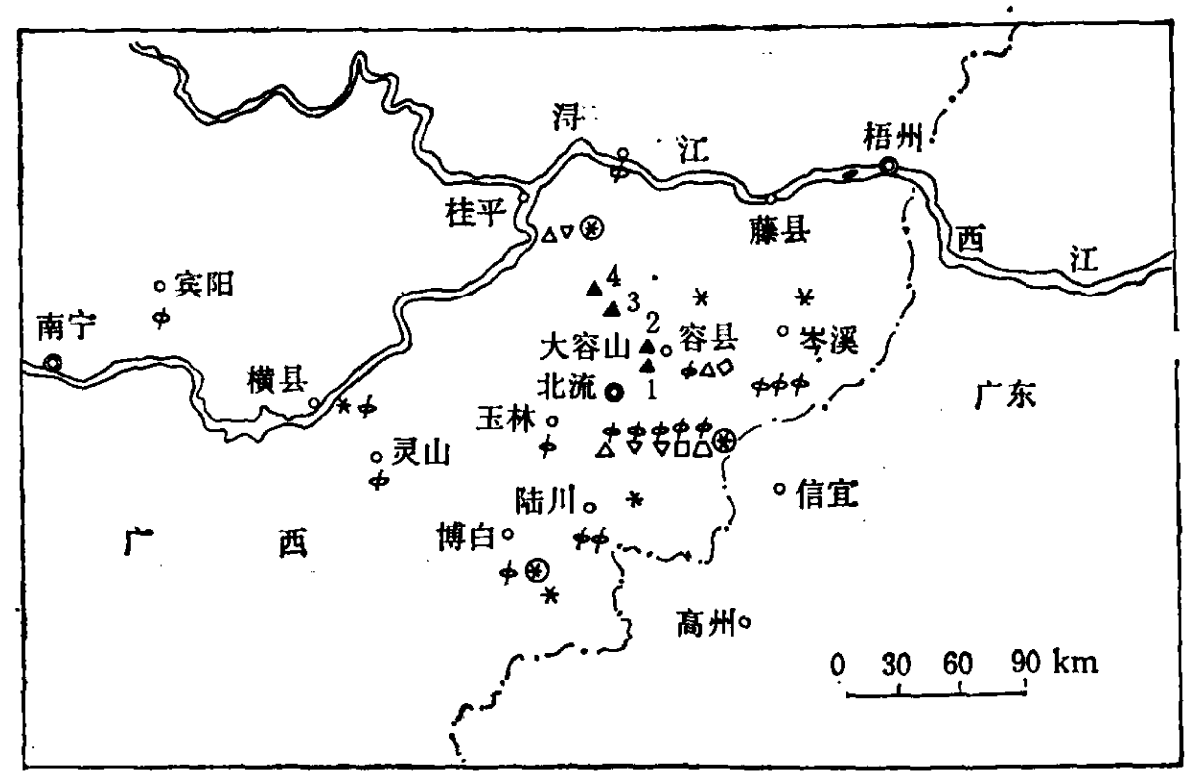

图 1 本文采样分布图

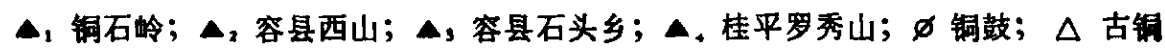

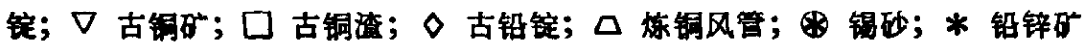


我们采集了北流型铜鼓 16 面, 冷水冲型铜鼓 1 面, 北流铜石岭及其邻区容县、桂平出土的 古铜矿 3 个、古铜锭 3 个、古铜渣 1 个、古铅锭 1 个、含渣炼铜风管 1 个和北流县周围地区的铅 锌矿 7 个和锡砂矿 3 个样品(图 1), 供本文研究之用. 我们测定了这批样品的铜锡铅含量和 铅同位索比值，然后应用分布场 (field) 对比的方法来探索北流型铜鼓的矿料来源等问题，拟 对当前铜鼓研究中的这个难题,作一些初步的研究.

\section{一、实 验方 法}

样品中铅的分离和富集,可按文献 [1]的电解沉积法. 但本文中的铅同位素比值, 是用 80 年代新型的 VG-354 质谱计测定. 所得结果, ${ }^{206} \mathrm{~Pb} /{ }^{204} \mathrm{~Pb},{ }^{207} \mathrm{~Pb} /{ }^{206} \mathrm{~Pb},{ }^{208} \mathrm{~Pb} /{ }^{206} \mathrm{~Pb}$ 比值的相对标 准误差分别为 $<0.05 \%,<0.01 \%$ 和 $<0.01 \%$.

样品的化学成份分析是用原子吸收光谱法和电子探针法. 后者采用多点测试、标样校正. 对铜锡铅的常量分析误差优于 $1 \%$.

实验结果分别列于表 1 和表 2 中.

表 1 广西北流型铜鼓的实验数据

\begin{tabular}{|c|c|c|c|c|c|c|c|c|c|}
\hline 序号 & 编号 & 出土地点 & 类型 & ${ }^{200} \mathrm{~Pb} /{ }^{20 .} \mathrm{Pb}$ & ${ }^{207} \mathrm{~Pb} /{ }^{006} \mathrm{~Pb}$ & ${ }^{208} \mathrm{~Pb} /{ }^{206} \mathrm{~Pb}$ & $\mathrm{Cu}(\%)$ & $\operatorname{Sn}(\%)$ & $\mathrm{Pb}(\%)$ \\
\hline 1 & 鼓-34 & 北流 & 北 流 & 18.460 & 0.84788 & 2.0986 & 88.68 & 8.60 & 0.96 \\
\hline 2 & 鼓-35 & 容县 & 北 流 & 18.347 & 0.84716 & 2.0874 & 75.65 & 14.39 & 5.57 \\
\hline 3 & 鼓-55 & 陆川 & 北 流 & 18.468 & 0.84802 & 2.0953 & 90.56 & 6.52 & 0.97 \\
\hline 4 & 鼓-60 & 玉林 & 北 流 & 18.103 & 0.85354 & 2.1075 & 86.02 & 11.2 & 0.22 \\
\hline 5 & 鼓-115 & 灵山 & 北 流 & 18.358 & 0.84459 & 2.0883 & 69.42 & 16.16 & 21.5 \\
\hline 6 & 鼓-146 & 岑溪 & 北 流 & 18.487 & 0.84452 & 2.0945 & 87.34 & 9.49 & 0.49 \\
\hline 7 & 鼓-156 & 北流 & 北 流 & 18.544 & 0.84422 & 2.0929 & 74.21 & 22.19 & 0.66 \\
\hline 8 & 鼓-161 & 北流 & 北 流 & 18.570 & 0.84201 & 2.0877 & 88.95 & 7.62 & 0.35 \\
\hline 9 & 鼓-163 & 横县 & 北 流 & 18.584 & 0.84342 & 2.0926 & 80.10 & 10.98 & 3.70 \\
\hline 10 & 鼓-308 & 北流 & 北 流 & 18.322 & 0.84813 & 2.1011 & 97.26 & 0.28 & 0.41 \\
\hline 11 & 鼓-139 & 北流 & 北 流 & 18.412 & 0.84915 & 2.1014 & 78.3 & 18.82 & 0.26 \\
\hline 12 & 鼓-149 & 宾阳 & 冷水冲 & 19.247 & 0.81679 & 2.0903 & 74.03 & 6.88 & 14.50 \\
\hline 13 & 鼓 -140 & 博白 & 北 流 & 18.566 & 0.85198 & 2.1165 & 69.61 & 12.0 & 12.0 \\
\hline 14 & 鼓-157 & 岑溪 & 北 流 & 18.811 & 0.84852 & 2.1118 & 77.71 & 19.1 & 0.66 \\
\hline 15 & 鼓-143 & 平南 & 北 流 & 18.364 & 0.85815 & 2.1177 & 72.5 & 7.50 & 13.5 \\
\hline 16 & 鼓-56 & 陆川 & 北 流 & 18.642 & 0.84656 & 2.1059 & 76.89 & 14.38 & 4.37 \\
\hline 17 & 鼓-32 & 岑溪 & 北 流 & 18.298 & 0.84708 & 2.1032 & 75.17 & 14.35 & 5.76 \\
\hline
\end{tabular}

\section{二、结果和讨论}

1. 北流型的 16 面铜鼓均出土于北流县及其邻区, 其铜锡铅的含量变化见图 2. 从图 2 看 
表 2 广西北流周围出土的矿产原料实验数据

\begin{tabular}{|c|c|c|c|c|c|c|c|c|c|}
\hline 序号 & 编号 & 出土地点 & 种类 & ${ }^{206} \mathrm{~Pb} /{ }^{204} \mathrm{~Pb}$ & ${ }^{207} \mathrm{~Pb} /{ }^{206} \mathrm{~Pb}$ & ${ }^{201} \mathrm{~Pb} /{ }^{200} \mathrm{~Pb}$ & $\mathrm{Cu}(\%)$ & $\operatorname{Sn}(\%)$ & $\mathrm{Pb}(\%)$ \\
\hline 1 & 8631 & 北流铜石岭 & 古铜矿 & 18.930 & 0.83826 & 2.0902 & 8.51 & & 4.04 \\
\hline 2 & 8632 & 北流铜石岭 & 古铜矿渣 & 18.481 & 0.84908 & 2.0946 & 2.37 & 0.18 & 0.92 \\
\hline 3 & 8633 & 谷县西山 & 古铜矿 & 18.581 & 0.85330 & 2.1091 & 7.46 & & 1.38 \\
\hline 4 & 8635 & 容县石头乡 & 古铜锭 & 18.348 & 0.85552 & 2.1033 & 97.84 & & 0.02 \\
\hline 5 & 8636 & 容县石头乡 & 古铅锭 & 18.258 & 0.85971 & 2.1227 & & & \\
\hline 6 & 8637 & 桂平罗系 & 古铜锭 & 18.404 & 0.86006 & 2.1209 & & & \\
\hline 7 & 8638 & 北流铜石岭 & 古铜锭 & 18.767 & 0.83986 & 2.0927 & 92.89 & & 0.16 \\
\hline 8 & 8639 & 北流铜石岭 & 古铜矿 & 18.816 & 0.83904 & 2.0917 & & & \\
\hline 9 & 8641 & 容县白良 & $P b-Z n$ 矿 & 18.697 & 0.84543 & 2.1110 & & & 8.01 \\
\hline 10 & 8643 & 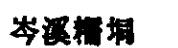 & Pb-Zn矿 & 18.318 & 0.86512 & 2.1287 & & & 83.15 \\
\hline 11 & 8644 & 岑湜媓竹 & $\mathrm{Pb}-\mathrm{Zn}$ 砣 & 18.820 & 0.8320 & 2.0867 & & & 65.61 \\
\hline 12 & 8645 & 岑漠诚㑈 & $\mathrm{Pb}-\mathrm{Zn}$ 矿 & 18.704 & 0.84281 & 2.1044 & & & 81.64 \\
\hline 13 & 8647 & 陆川坡的 & $\mathrm{Pb}-\mathrm{Zn} \not \boldsymbol{b}^{2}$ & 18.247 & 0.86367 & 2.1170 & & & 6.64 \\
\hline 14 & 8649 & 博白宁原 & $\mathrm{Pb}-\mathrm{Zn}$ 砧 & 18.374 & 0.86252 & 2.1227 & . & & 12.29 \\
\hline 15 & 8651 & 横县 & $\mathrm{Pb}-\mathrm{Zn}$ 矿 & 18.352 & 0.86173 & 2.1235 & & & 13.24 \\
\hline 16 & 8664 & 北流铜石岭 & 燎铜风管 & 18.715 & 0.83694 & 2.0794 & 0.31 & & 4.04 \\
\hline 17 & 8658 & 搏白䧓任乡 & 锡砂 & & & & & 14.97 & 0.05 \\
\hline 18 & 8659 & 北流石宽乡 & 锡砂 & & & & & 63.57 & 0.69 \\
\hline 19 & 8657 & 桂平西山乡 & 锡础 & & & & & 41.50 & 0.04 \\
\hline
\end{tabular}

出,只有一面铜鼓属红铜制品(鼓-308), 其锡铅含量 $<2 \%$; 而 8 面属锡青铜 $(\mathrm{Sn}>2 \%, \mathrm{~Pb}<$ $2 \%)$; 7 面属铅锡青铜 $(\mathrm{Sn}>2 \%, \mathrm{~Pb}>2 \%)$ 制品 ${ }^{[3]}$.

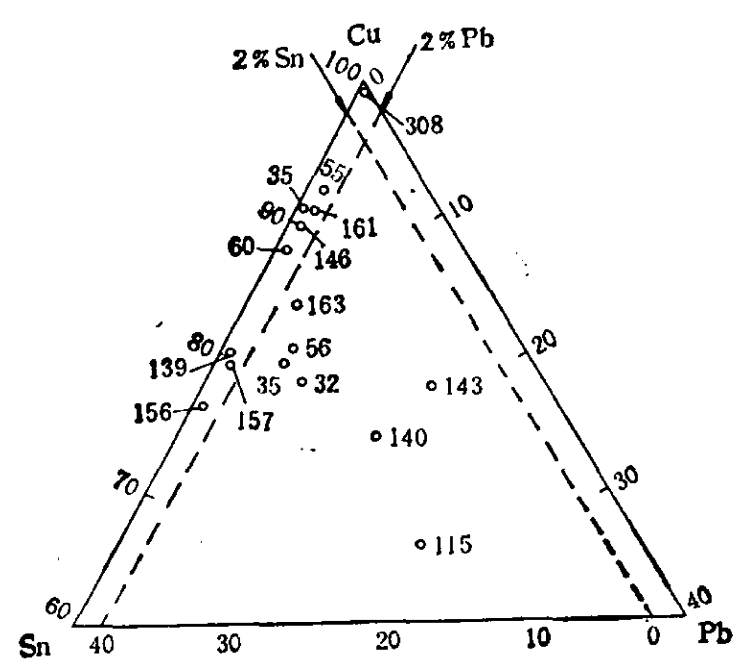

图 2 广西北流型 16 面铜鼓的铜锡铅含量分布图

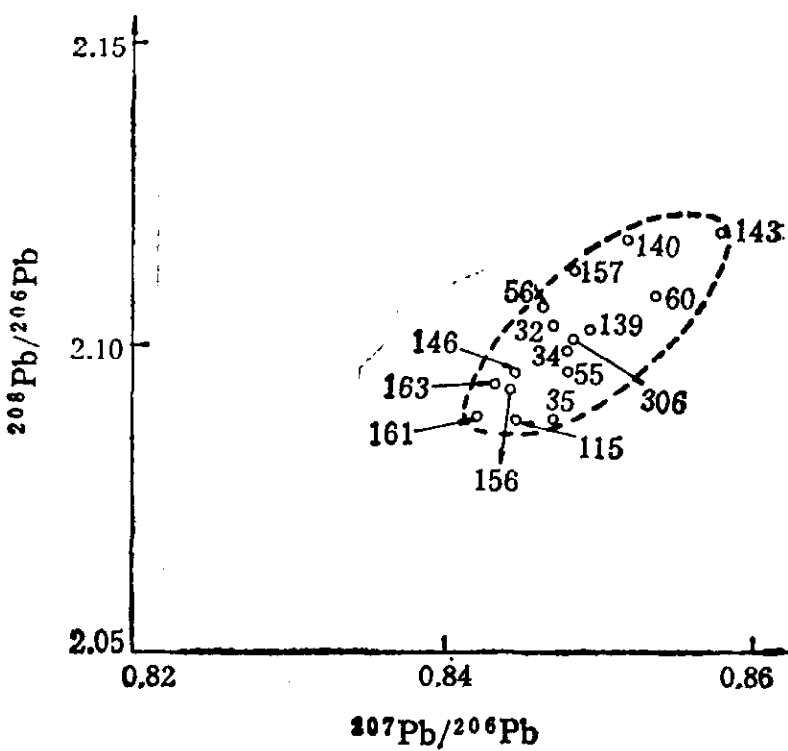

图 3 北流型铜鼓的铅同位素分布图 
铜锡铅成份的变化是铜鼓制作工艺演化的一个重要标志.一般地认为 ${ }^{[4]}$ 早期的铜鼓由纯 铜 (又称红铜)制作为多数. 随着合金的优越性被人们逐步地认识，中、后期的铜鼓采用铜锡， 以及铜锡铅合金的为数占绝大部分. 只要适当地选用铜锡铅的比例，就为制造大型薄壁铜鼓 提供了物料的基础。

从 16 面铜鼓的成份变化,可以粗略地反映了整个北流型铜鼓从早期 (汉代) 延至晚期(隋 唐),约 700-800 年间的时代变迁 ${ }^{[4]}$. 为此对这批样品的研究具有相当的普遍性.

2.16 面北流型铜鼓的铅同位素比值分布得比较集中 (图 3). ${ }^{200} \mathrm{~Pb} /{ }^{206} \mathrm{~Pb}$ 比值为 $0.842-$ $0.858,{ }^{208} \mathrm{~Pb} /{ }^{206} \mathrm{~Pb}$ 为 $2.09-2.12$, 变化均不超过 $2 \%$, 而北流县出土的 5 面铜鼓(表 1 ), 其 ${ }^{207} \mathrm{~Pb} /$ ${ }^{206} \mathrm{~Pb}$ 比值的平均值为 $0.846,{ }^{208} \mathrm{~Pb} /{ }^{206} \mathrm{~Pb}$ 为 2.10 . 从这些铅同位素值变化范围少, 和北流县铜 鼓铅平均比值落在北流型铜鼓之间，可以推断它们所用的矿料来源比较集中,可能来自某处及 其毗邻地区.

表 1 中还列出了 1 面属冷水冲型铜鼓(鼓-149)的铅同位紊数据, 其比值远离北流型铜鼓 的分布范围(图 4). 该鼓出土于广西宾阳(图 1), 远离北流一带, 说明它可能有其它的矿料来 源。

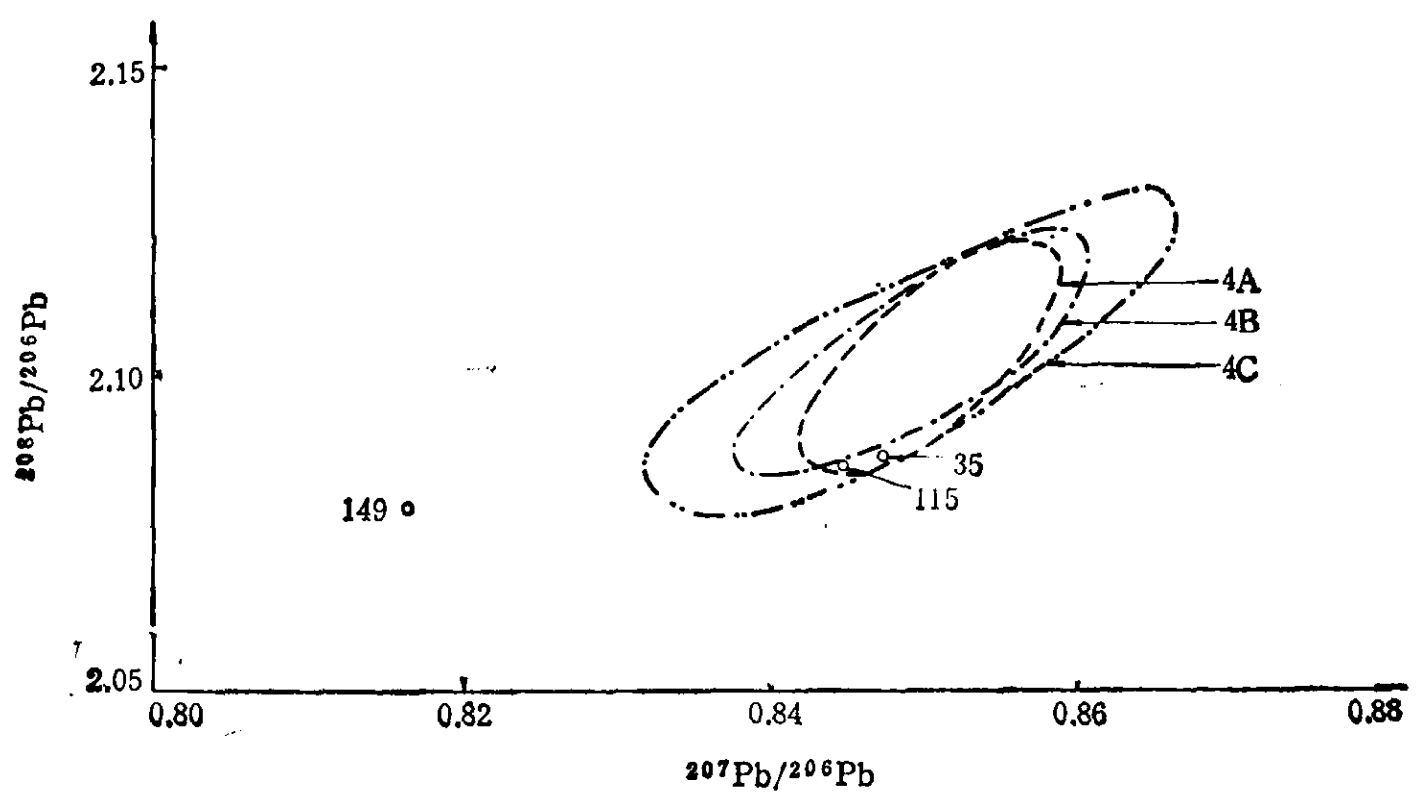

图 4 本文 34 个样品的铅同位索分布图

- - 北流型铜鼓的铅同位素分布图，149 为冷水冲型铜鼓，35，115 为北流型铅锡 青铜鼓; - - - - 北流铜石岭及其周围地区出土的古铜锭、古矿渣、古铜矿石的铅 同位来分布图; - - - - - 北流周国地区出土的铅锌矿、古铅锭和炼铜风管的铅同位 采分布图

3. 图 4B 展示了来自北流铜石岭、容县和桂平等 4 处的古铜矿、古铜锭和古矿渣的铅同位 紊比值分布图. 从表 2 数据(详图因篇幅有限，从略)可以看出北流的 2 个古铜矿和 1 个古铜 锭的实验点十分接近，这表明出土的古铜锭确由当地的铜矿料冶炼而成. 来自容县的铜锭和 铜矿的实验点也比较接近,而桂平的古铜锭数据则远离了上述的二组数据. 由此可见,用铅同 位素来揭示矿料的分带性还是有一定的规律性. 可喜的是, 由古铜矿和古铜锭的铅同位素构 成的分布场 (图 4B) 覆盖了几乎整个铜鼓的分布场 (图 4A). 又从铜鼓的实验点来看, 比较集 中在铜石岭及毗邻的容县西山和石头乡的古铜矿和古铜锭分布区内. 由此，可进一步地推断 
广西北流型铜鼓的矿料也主要来自这些地区.

4. 在第 1 小节中已指出, 对于所研究的 16 面北流型铜鼓中有 7 面属铅锡青铜制成（图 2). 目前, 人们普遍地认为这些含铅量大于 $2 \%$ 的青铜样品, 是用外来的含铅矿料合铸而成 的. 那么这些铸造铜鼓的铅矿料从何处来? 我们曾在北流县民乐乡采集到一些铅锌矿料, 但 含铅量为 $0.11 \%$,不易作为铅的原料. 但我们在北流县邻区的 5 处采集了七个铅锌矿,一个古 铅锭和一个带有残渣的炼铜风管(含铅 $4 \%$ ), 并将其铅同位素的比值绘成图 4C (详图因篇幅 所限、从略). 这些铅同位素比值的变化可达到 $4 \%$,要比铜鼓的变化范围大, 并且把铜鼓的分 布场完全复盖(图 4C 和 4A). 这说明北流型铜鼓中的铅矿料, 可以来自北流县邻近地区的含 铅矿料。值得注意的是,图 4B 并没有完全覆盖图 4A, 其中有二个样品(鼓-35，-115)含铅量 高,分别为 $5.5 \%$ 和 $21.5 \%$ (表 1). 但这两个样品的实验点正好落在由铅矿料构成的分布场内 (4C). 由此可见，铜鼓中的铅矿料可来自北流周围的地区是比较可信的.

样品中的一个古铅锭 (8636) 出土于容县的石头乡, 与此同时, 还出土了古铜锭 (8635), 但这两个铅同位素比值相差很大. 这说明它们不是来源于一个含铜铅的共生多金属矿床. 古 铅锭的铅同位素也与容县白良的铅锌矿 (8641) 相差很大. 从目前的实验数据来看, 古铅锭的 铅矿来源不一定在出土的容县地区,它可以来自与其同位索比值相近的邻区, 如横县、博白或 岑溪等处。如果这点确实, 那么邻区冶炼出铅锭, 再运至北流铜石岭或容县一带铸造铜鼓, 也 就成为可能。

5. 从 16 面北流型铜鼓的成份分析,有 15 面分别含锡量大于 $2 \%$ (图 2), 其中最高的可达 $22 \%$ 。在我们实地考察中,已收集到北流石窝乡 (8658)及其邻区博白(8658)、桂平(8657)出土 的锡砂矿料。经化学分析, 它们含锡量高达 $15-64 \%$ (表 2), 有可能为铸造铜鼓提供了锡的矿 料来源.

\section{三、结 语}

综合上述的讨论, 根据铅同位素作为“指纹”, 由实验结果推断出广西北流型铜鼓的矿料来 源于北流铜石岭及其邻区, 如容县西山、石头乡一带. 这个结果与文史资料以及野外考察相一 致*.

我国考古学界著名学者、已故的夏弴先生曾指出: “今天, 我们不仅研究青铜器本身的来 源, 即它的出土地点. 还要研究它的原料来源, 包括对古矿的发掘和研究. 这是中国古代青铜 器研究的一个新领域, 也是中国考古学新开辟的一个领域”(s). 本文正是在这个新的领域中作 了一个初步的探索.

致谢：对中国科学技术大学副教授李志超的指导,广西博物馆馆长蒋廷瑜的支持, 天津地质矿产研究所 同位美实验室主任黄承义的制助,表示衷心的感谢.

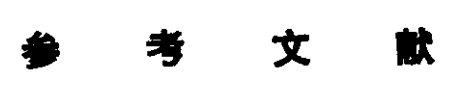

[1] 陟于成策,考古, 1985, 11: 1032-1037.

[2] 广西壮族自治区文物工作队,考古, 1985, 5: 404-410.

[3]闻广,地质评论, 28(1980), 4: 331-340.

[4] 中国古代铜吱研究会,古代铜鼓学术讨论会论文紫,文物出版讨, 1980, 1-15.

[5] 工期等,考古学报, 1982, 1: 1-14.

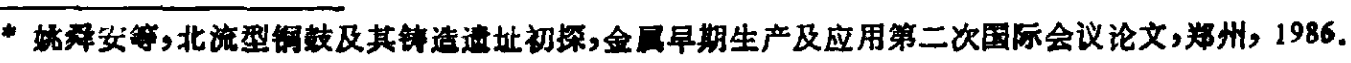

